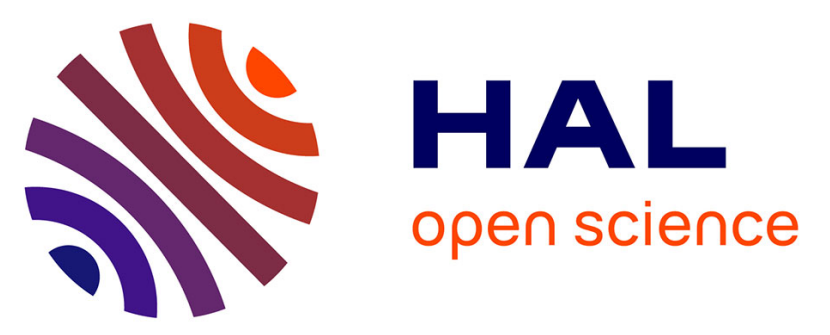

\title{
NOVELICA: A Visual Novel System to Make People Forget Their Negative Feelings on Mathematics
}

Nobumitsu Shikine, Toshimasa Yamanaka, Letizia Jaccheri, Javier Gomez, Junichi Hoshino

\section{To cite this version:}

Nobumitsu Shikine, Toshimasa Yamanaka, Letizia Jaccheri, Javier Gomez, Junichi Hoshino. NOVELICA: A Visual Novel System to Make People Forget Their Negative Feelings on Mathematics. 17th International Conference on Entertainment Computing (ICEC), Sep 2018, Poznan, Poland. pp.329333, 10.1007/978-3-319-99426-0_39 . hal-02128607

\section{HAL Id: hal-02128607 https://hal.inria.fr/hal-02128607}

Submitted on 14 May 2019

HAL is a multi-disciplinary open access archive for the deposit and dissemination of scientific research documents, whether they are published or not. The documents may come from teaching and research institutions in France or abroad, or from public or private research centers.
L'archive ouverte pluridisciplinaire $\mathbf{H A L}$, est destinée au dépôt et à la diffusion de documents scientifiques de niveau recherche, publiés ou non, émanant des établissements d'enseignement et de recherche français ou étrangers, des laboratoires publics ou privés. 


\title{
NOVELICA: A Visual Novel System to Make People Forget Their Negative Feelings on Mathematics
}

\author{
Nobumitsu SHIKINE ${ }^{1}$, Toshimasa YAMANAKA ${ }^{2}$, Letizia Jaccheri ${ }^{3}$, \\ Javier Gomez ${ }^{4}$, Junichi HOSHINO ${ }^{5}$ \\ University of Tsukuba, $\left\{{ }^{1}\right.$ Graduate School of Integrative and Global Majors, ${ }^{2}$ Faculty of Art \\ and Design, ${ }^{5}$ Faculty of Engineering, Information and Systems $\}$, Tsukuba, Japan \\ ${ }^{3,4}$ Norwegian University of Science and Technology, Trondheim, Norway

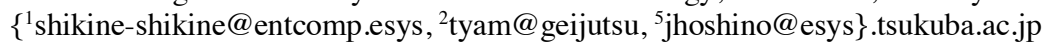 \\ $\left\{{ }^{3}\right.$ letizia.jaccheri, ${ }^{4}$ javier.escribano\}@ntnu.no
}

\begin{abstract}
In this paper we present a new visual novel system "NOVELICA" which employed Japanese anime like character agent and segmented the lesson to conversation size. It is designed to make exciting pace like an entertainment content than ordinary lessons and it is easier to control progression than video learning. We compared with NOVELICA to previous visual novel system and video learning system. And we found that NOVELICA can reduce stress and keeping arousal in learning mathematics, and it makes easier to touch mathematics content.
\end{abstract}

Keywords: e-Learning, Remedial Education, Math Anxiety, Video Learning, Visual Novel, Instructional Pacing

\section{Introduction}

There are many students who are not good at or have anxiety towards math [1]. In many cases, math above the high school level requires cross-referencing of knowledge of various units and, depending on the student, creating the need for instructional pacing that suits the individual.

In recent years, there have been many examples of adaptive learning that introduce an e-Learning system as a follow-up to the one-to-many lecture format. In particular, the self-study system for visual lessons is easy to match to a schedule and is often used in universities and corporate training. However, they do not take into account the pace of students usually, there is no interaction with a teacher and it is difficult to maintain the motivation to study [2], which leads to stress during the learning process. It is known that stress during studying puts pressure on working memory and has a negative effect on learning study contents. Therefore, stress management is becoming a popular matter to work on in schools and at home [3][4]. Although stress comes from various sources, such as from a dislike of a subject or circumstances at home, either source negatively affects learning.

There are numerous scales when speaking generally about instructional pacing, and we can even consider choosing what to study on a certain day based on a monthly study schedule as instructional pacing. Conventional systems split study into sections such as 
"trigonometric functions" and "differentials and integrals" according to a learner's comprehension and even use single lessons to keep up pace with the student. However, there has been no consideration made so far for attentive pacing corresponding to motivation and mood for studying in one lesson.

To consider this, it will be necessary to review a new time structure that differs from that held by existing contents such as videos. Therefore, this study focuses on the time structuring of e-Learning systems and developed NOVELICA.

\section{NOVELICA}

NOVELICA is designed to make exciting pace on visual novel content by segmenting to conversation sized block. The existing self-study e-Learning systems can be split up into the two types of automatic progression and manual progression when classifying them based on the pace of lesson progression, and each has their own issues.

The video lesson system (automatic progression) can be watched with comfort, and since the visual novel system (manual progression) has the time structural advantage of being able to carefully read content, we examined a time segmenting method that allows us to incorporate both of these.

NOVELICA is a visual novel system which splits lessons into time segments of single response prompts of conversations in order to solve the aforementioned issues [5]. These are referred to as "blocks". One block consists of a single voice file, and text and images are displayed in sync with the conversation from that voice file. One block therefore maintains prosodic information intended by the teacher (Fig 1,2).

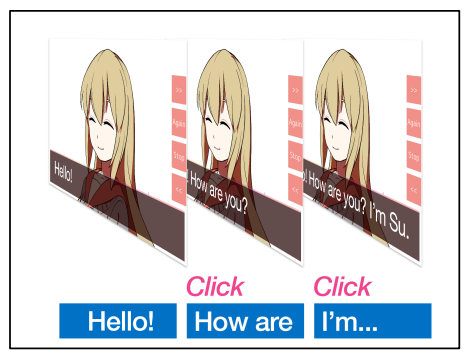

Fig. 1. Timing Structure of Novel Game

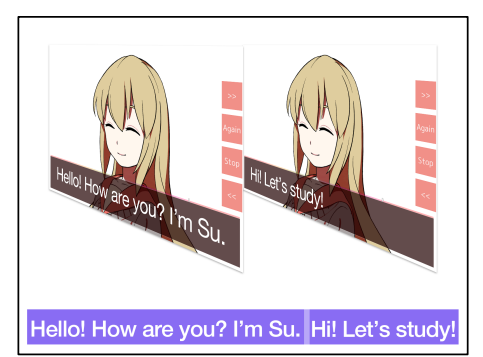

Fig. 2. Timing Structure of NOVELICA

Because one conversation's asking and replying takes 5 to 10 seconds, the recommended length of a block is 5 to 10 seconds. There is also no essential need for clicks in between each block, and a video experience is made possible by having the game automatically progress. A big difference when compared to video is that the producer can insert click prompts (response prompts) in between blocks anywhere they choose. In other words, they can basically progress it automatically, like a video, while leaving it to the student to progress in situations where they want to put emphasis on speech or give the student time for deliberation. In addition, it is a semi-automatic type system that allows the user to stop at the current block or jump to a block of her choice in the middle of automatic progression. Since speech can be cued for each block, listening 
back to topics can be carried out smoothly. And inserting click prompts (response prompts) makes the learner keep suitable arousal level. This is because learner does not know where the prompts are and they have to be awake to respond. Teacher can design pace of the lesson and learner can control its progress adjusting to individual motivation and feeling.

We developed the first NOVELICA content is "AKAHONe! Prototype A" (Fig 3). This content is designed to reduce the negative feeling on mathematics by putting exciting conversation like an entertainment video. And it focused its speedy progress pace. The content consists of two characters' conversation. The first one is a high school girl character, $\mathrm{Su}$, and she acts as a teacher. The second one is a high school boy, Shikine, and he acts as a learner. Both characters are drew like a Japanese anime style and in comical way because it is popular among young people. Learners can superimpose themselves on Shikine and watch content of Su's lesson.
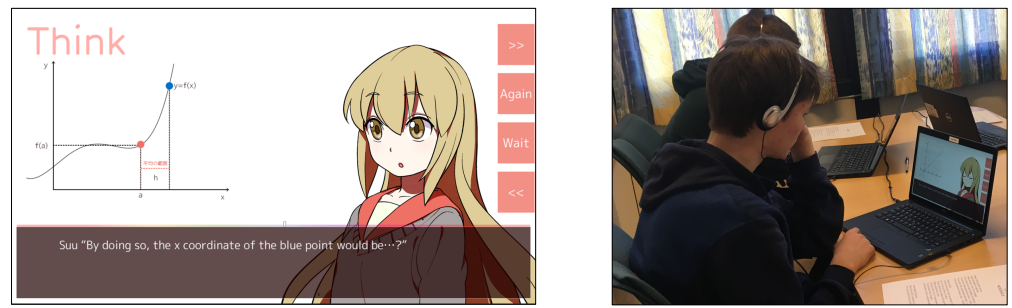

Fig. 3 (left). NOVELICA content "AKAHONe! Prototype A"

Fig. 4 (right). The workshop "Games, culture and science for boys and girls"

\section{Evaluation}

Two evaluation were conducted for NOVELICA. The first one was conducted to compare NOVELICA to other type of e-learning system [5]. 21 Japanese men and women who had graduated high school and reported to have weak interests at math cooperated as participants for the experiment. We used Two-Dimensional Mood Scale[6] and POMS[7] as evaluation indicators. The results indicated that NOVELICA's segmentation makes it possible to create individually suited lesson paces and acts as a time structure that reduces stress during learning and assists with comprehension. The second one was held during the workshop "Games, culture and science for boys and girls". This event took place at the Gunnerus Library (Trondheim, Norway). (Fig 4) Participants were 10 Norwegian men and women aged 13 to 70 years old. After playing NOVELICA, participants answered mathematical questions and feeling questions about NOVELICA. And we measured how long participant takes for each block and whole lesson time they took. Among the impressions of the participants, there were things that "I liked that it taught a lot of information in such a short time" and "I like the way it kind a looked like anime". This is thought that our content was effective for touching mathematics. But some participants said "It was too fast to understand" and we found they tend to take a longtime (more than 1minute) for thinking to respond to a 
prompt in playing NOVELICA. It will be our next task to clarify the relationship between thinking time and whether or not leaner can enjoy lesson content.

\section{Conclusion}

NOVELICA is a visual novel system which segment the lesson to conversation size and make progress automatic. Developer can design exciting paced lesson on NOVELICA to make people forget their negative feelings on mathematics with Japanese anime like characters. For the future work, clarify the relationship between thinking time and whether or not leaner can enjoy lesson content and we will develop other subjects of NOVELICA content.

\section{Acknowledgements}

This work has been partially supported by NTNU ARTEC and carried out during the tenure of an ERCIM "Alain Bensoussan" fellowship. The authors would like to thank Alexandra Angeletaki for organizing the international experiment workshop at the Gunnerus library of NTNU. We also give deep gratitude to the staff of indie game developer team Chloro and the translator David Evelyn.

\section{References}

1. Gijsbert Stoet, Drew H. Bailey, Alex M. Moore, David C. Geary: Countries with Higher Levels of Gender Equality Show Larger National Sex Differences in Mathematics Anxiety and Relatively Lower Parental Mathematics Valuation for Girls, PLoS One. 2016; 11(4): e0153857.Published online 2016 Apr 21. doi: 10.1371/journal.pone.0153857 (2016)

2. R Nakamura, A Inoue, S Ichimura, K Okada, Y Matsushita: “Ghost-Tutor”: A Learning Support System Suggesting Learning Pace for on-Demand Learning, IPSJ 47(7), pp.20992106 (2006)

3. Rose K. Vukovic, Michael J. Kieffer, Sean P. Bailey, Rachel R. Harari: Mathematics anxiety in young children: Concurrent and longitudinal associations with mathematical performance, Contemporary Educational Psychology Volume 38, Issue 1, January, pp.1-10 (2013)

4. Talia Berkowitz, Marjorie W. Schaeffer, Erin A. Maloney, Lori Peterson, Courtney Gregor, Susan C. Levine, Sian L. Beilock: Math at home adds up to achievement in school, Science. Vol. 350, October 9, p.196. (2015)

5. Nobumitsu Shikine, Toshimasa Yamanaka, Junichi Hoshino:A Game System for Learning Mathematics with Pacing Considering Individual Motivation and Feeling. ICEC 2017: 169176 (2017)

6. Y Sakairi, K Nakatsuka, T Shimizu: Development of the Two-Dimensional Mood Scale for self-monitoring and self-regulation of momentary mood states, Japanese Psychological Research 55(4), (2013)

7. Kazuhito Yokoyama: POMS tanshukuban tebiki to jirei kaisetsu (in Japanese), KANEKOSHOBO (2005) ISBN 9784760840144 